\title{
Agôn
}

Revue des arts de la scène

Critiques | Saison 2012-2013

\section{Living!, Textes du Living Théâtre, mise en scène Stanislas Nordey}

Individu et collectif

\section{Caroline Châtelet}

\section{(2) OpenEdition}

Journals

Édition électronique

URL : http://journals.openedition.org/agon/2363

DOI : 10.4000 /agon.2363

ISSN : 1961-8581

Éditeur

Association Agôn

Référence électronique

Caroline Châtelet, "Living!, Textes du Living Théâtre, mise en scène Stanislas Nordey », Agôn [En ligne], Critiques, mis en ligne le 04 janvier 2013, consulté le 23 septembre 2020. URL : http:// journals.openedition.org/agon/2363; DOI : https://doi.org/10.4000/agon.2363

Ce document a été généré automatiquement le 23 septembre 2020.

Association Agôn et les auteurs des articles 


\section{Living!, Textes du Living Théâtre, mise en scène Stanislas Nordey}

Individu et collectif

Caroline Châtelet

\section{RÉFÉRENCE}

Living!, textes de Julian Beck et Judith Malina, mise en scène de Stanislas Nordey Théâtre des Quartiers d'Ivry - du 10 au 21 décembre 2012

http://www.theatre-quartiers-ivry.com

1 Comme comédien, Stanislas Nordey est connu pour son jeu stylisé, où la diction proche parfois de la profération travaille à une mise en tension du corps de l'acteur. Un jeu où les bras occupent un rôle important - «Il faut savoir placer ses bras. Surtout au théâtre » dixit la critique du Monde Brigitte Salino'.

Jeu stylisé et néons : deux caractéristiques que l'on retrouve dans Living!, proposition mise en scène par Nordey et réunissant les élèves comédiens du TNB. Construit autour des écrits de Julian Beck et Judith Malina, les deux fondateurs du Living Théâtre, ce spectacle signe aussi le départ de Nordey du poste de responsable pédagogique de l'École du Théâtre national de Bretagne - où lui succède Éric Lacascade. Les écrits de la compagnie américaine de théâtre expérimental ayant été importants pour le jeune comédien Nordey à sa sortie du Conservatoire, celui-ci a souhaité les voir réinvestis par de jeunes acteurs. Living! constitue donc un geste de transmission fort, offrant une traversée des multiples phases d'engagements du Living Théâtre - la compagnie ayant produit poèmes, textes politiques, interviews ou écrits théoriques. Dans ce parcours séquencé, les comédiens donnent les textes seuls ou en petit nombre, tandis qu'un groupe se fait et se défait au second-plan. À la constitution du collectif et à ses évolutions se superpose l'individu, être agissant en son nom propre. C'est bien d'ailleurs sur les individus que tout se joue. Car ce dispositif minimal, où tout se dit de face, dans une position directe proche parfois de la harangue, mise tout sur les 
capacités de chaque comédien. À tel point qu'un sentiment étrange s'installe : celui d'assister à la tentative - plus ou moins heureuse - de reproduction du jeu de Nordey. Mais que l'on connaisse ou pas cette interprétation particulière, le constat est le même : difficile d'entendre le texte, tant le vague mimétisme qui règne relève plus d'une absence de direction d'acteurs que d'un choix motivé. Et si certains jeunes comédiens réussissent à tirer leur épingle du jeu, il se déploie dans Living! autre chose. En préférant à un travail choral l'interprétation isolée, le spectacle se donne comme un pur produit de fin d'école, adapté au fonctionnement individualiste de l'institution théâtrale. Inconsciemment, Living! offre une audition d'une heure trente, où chaque jeune acteur doit à tour de rôle démontrer ses capacités propres. Que le collectif demeure éternellement à l'arrière-plan et se défasse lentement résonne alors étrangement avec les évolutions des utopies et de l'engagement théâtral de la seconde moitié du XXe siècle, Living Theatre compris.

\section{NOTES}

1. Savoir se servir de ses bras, art maîtrisé dans Clôture de l'amour, article paru dans l'édition du 06/10/11 du journal Le Monde. 